\title{
L'UTILLATGE DE LA LLAR ALS DARRERS SEGLES MEDIEVALS
}

\author{
TERESA VINYOLES I VIDAL \\ Universitat de Barcelona
}

\begin{abstract}
SUMARI
1. L'espai privat. 1.1. La casa. 1.2. Tancar la casa.- 2. Les tasques de la llar i el seu utillatge. 2.1. La neteja: Escombrar o agranar. Orejar i "espalmar" la roba. La bugada. Fregar plats. Fer els llits. 2.2. "Casta fuit, domum servavit, lanam fecit": Filar. Utillatge casolà per filat $i$ costura. 2.3. L'alimentació: El foc. Pastar. Conservar i emmagatzemar aliments; Cuinar.- Conclusions.
\end{abstract}

\section{L'ESPAI PRIVAT}

\subsection{La casa}

La casa és l'àtom del món medieval'; es fa difícil separar l'edifici de les funcions que ha de complir. La llar és l'espai de la família, de les tradicions que la mantenen, de l'autoritat paterna que la dirigeix, part $\mathrm{i}$ símbol del patrimoni: la casa és tot això tant pel senyor com pel camperol,

\footnotetext{
'Per la llar medieval hem treballat amb: Paul ZUMTHOR, La medida del mundo, Madrid, Cátedra, 1994; (especialment el capítol "La morada", pp. 51-136); Montserrat RoIG, Digues que m'estimes encara que sigui mentida, Barcelona, Edicions 62, 1991, pp.120-128; Norman POUNDS, La vida cotidiana: Historia de la cultura material, Barcelona, Crítica, 1992; (especialment el capitol "La intimidad del hogar", pp. 245-290).

"Anuario de Estudios Medievales", 29 (1999)
} 
tant a pagès com a ciutat. La casa és el domicili, l'espai privat, el lloc on es concentren els valors de la vida, l'escenari d'amors, desamors, naixements i morts.

Però la casa medieval és també un punt de producció i de consum, que tendeix sovint a ser força autosuficient; les cases acostumaven a ser obradors on es produïen la majoria de productes bàsics per la vida de la família, per la qual cosa hi havia utillatge divers per preparar els aliments, conservar queviures, confeccionar vestits, tenir cura dels malalts, criar els fills, elaborar productes de neteja i remis. La llar era, així mateix, l'escola on s'educava les nenes que, generació rera generació, rebien de llurs mares, àvies o mestresses, coneixements molt diversos, dels que les tasques domèstiques n'eren només una part.

Les cases alt medievals eren petites, no tenien divisions interiors, o només en tenien una per separar l'espai on hi havia el foc; es dormia en un racó, es cuinava a l'altre, es treballa a tot arreu. Fins i tot les torres romàniques ens mostren un espai estret, fosc i poc confortable, gens apropiat per fer-hi estada una família senyorial. Després l'hàbitat tindrà cada cop una estructura més complexa, de manera que tant la casa burgesa com el mas baix medieval ens mostren espais específics per cada una de les diverses activitats que s'hi desenvolupaven, i també utensilis apropiats per cada una de les tasques que s'havien de realitzar pel confort de la llar i dels seus estadants.

En aquest treball de record i d'homenatge a la companya medievalista i mestressa de casa que ens ha deixat, em proposo estudiar les tasques domèstiques i els utensilis que es feien servir per realitzar-les durant els darrers segles medievals. Per aquesta tasca he cregut interessant analitzar a la vegada el parament de la llar, l'utillatges i l'ús que se'n feia. He treballat a partir de les necessitats considerades bàsiques: aixopluc, aliment, higiene, vestit. De tota manera cal tenir en compte que el necessari i el superflu sovint és força relatiu. Cada època, de vegades cada generació i cada grup social, opera a partir d'uns barems: el que era acceptable en el context històric d'una època, o d'una classe, pot no ser-ho per una altra. Així els llums, el subministrament d'aigua, els equips sanitaris mínims, eren luxes reservat a les classes privilegiades als segles XI i XII i es difongueren després vers grups més amplis de la societat baix medieval i moderna.

Tot i aquesta relativitat em proposo analitzar amb quins mitjans tècniques $\mathrm{i}$ amb quin enginy $\mathrm{i}$ esforç es resolien les necessitats que hem anomenat bàsiques. Utilitzaré essencialment inventaris, però també 
processos, fonts literàries, pintura i miniatura; més difícil es fa treballar amb objectes procedents de jaciments arqueològics. La major part dels estris quotidians s'han fos al llarg dels segles, ja que la majoria d'objectes eren de materials caducs. Constatem, per exemple, que els materials ceràmics, abundats a les excavacions, són més aviat escadussers en els inventaris i les imatges de l'època. També cal tenir en compte que a l'hora de tipificar les restes que han quedat s'ha simplificat molt, els inventaris catalans del XIV i XV citen més de vuitanta estris diferents de terrissa, molts dels quals no es poden identificar amb precisió.

\subsection{Tancar la casa}

La casa és primer de tot un aixopluc pel grup familiar que hi habita; dóna una idea de dins i de fora, posa ordre en el caos, protegeix, crea un espai íntim. En aquest sentit els primers estris que considerarem són els sistema de tancar la casa: claus, panys, forrellat, baldes, llisquets.

Així descriu un inventari del segle XV la doble entrada d'un mas de Rubí: la porta forana o portal major que donava pas al pati, i la porta de la casa: "Lo portal major de la dita casa ab son forrellat e tres panys, baldes e anell e golfos... En la entrada de la dita casa, o mas, fou atrobat: dues claus de porta, lobes, qui stan en un bastó"2.

No només la porta que donava entrada a la casa des de l'exterior, sinó també espais interiors com cambres, cofres o armaris es podien tancar amb pany i clau. Les claus que hi havia en una casa urbana dels grups més benestants les trobem descrites al llibre de comptes de la noble Sança Ximenis de Foix, que va llogar una casa a Barcelona, propietat d'un ciutadà: "A primer d'octubre (de 1441) entré en le case de miser Pere Jofre, quondam, e foren-me dades per se muler les claus qui són dues de les portes foranes, e una de la cambre pres la porte, e una de l'astudi, e altra de la cambre pres l'astudi, e una de l'armeri de l'astudi, e una de la cambre de la carrere, e una de la cambre pres le cuine. Son entre totes les claus vuit" ${ }^{3}$.

\footnotetext{
${ }^{2} \mathrm{AHCB}$, Notarials I, 10.

${ }^{3}$ El llibre de comptes com a font per a l'estudi d'un casal noble a mitjan segle XV. Primer llibre memorial começat per la senyora dona Sanxa Ximenis de Fox e de Cabrera e de Novalles 1440-1443, Barcelona, Fundació Noguera, 1992, pp. 119-120.
} 
A més en va fer fer d'altres que pagà de la seva butxaca: per la casa de la llenya, per la cuina i pel rebost fa fer claus llobes, és a dir que tancaven i obrien uns panys amb una peça de ferro; també feu fer una clau per l'escala del terrat, dues per les cambres del costat del terrat, una per la cambra de dalt, quatre claus pels armaris de la cambra del carrer. En total hi havia 19 claus.

La mestressa de casa, o una serventa de confiança anomenada clauera, era la dipositària de les claus. De nit la porta forana havia de romandre tancada; es fa molta incidència en que la casa honesta ha d'estar tancada de nit. Les portes només restaven obertes a partir d'entrada de fosc a les cases del prostíbul públic $\mathrm{i}$ als banys. Interrogat un ciutadà sobre la posició de la porta de la seva veïna afirmava: "de dies e de nits no és sinó porta de bany". En un altra informació els consellers barcelonins preguntaven de forma insistent a tots els testimonis "si de nits la dita dona te la porta uberta", un d'ells responia que no ho sabia, "per tant com ell testimoni tantots com és nit tanque la porta e no sab qui s'obre ni qui-s tanca"4. De nit, doncs, la porta es tancava i la clau quedava guardada a la cambra principal, és a dir al dormitori dels amos; de vegades es posava també per dintre una balda. L'endemà al matí la mestressa, o la clauera, a punta de dia, obria la porta.

\section{LES TASQUES DE LA LLAR I EL SEU UTILLATGE}

\subsection{La neteja}

Cal dir que l'odre que s'estableix en una llar medieval és diferent al sentit d'ordre que podem tenir avui. A les cases hi havia pocs armaris i la major part d'objectes estaven guardes especialment en caixes, arquibancs $i$ cofres, moltes vegades tancats amb pany i clau. També hi havia coses $\mathrm{i}$ cosetes posades en paneres, cistelles, gerres, sacs, caixetes.

Cada dia es procedia a fer una neteja mínima de les cambres més transitades de la llar, es fregaven els plats i es feien els llits. "Un rossí m'ha donade una pernada e jo no puc fet lits ni puc levar les scudelles ni puc fer

\footnotetext{
${ }^{4}$ Teresa VINYOLES, Unes notes sobre les marginades a Barcelona als segles XIV $i \mathrm{XV}$, "Acta Historica et Archaeologica Mediaevalia", 2 (1981), pp. 126 i 131 respectivament.
} 
res"5, afirmava una serventa en un procés. A més sembla que es feia una neteja més a fons el dissabte, probablement per mostrar que la casa era cristiana i que es treballava de manera ostensible el dia prohibit als jueus.

\section{Escombrar o agranar}

Una tasca que trobem documentada, tant pel que fa a les fonts escrites com inconogràfiques, és escombrar, que rep el nom d'agranar, derivat de la tasca de recollir el gra de l'era. En cancvi, no trobem cap esment a fregar el terra amb aigua i baieta. En el judici que acabem de citar podem continuar llegint com la vella serventa demanava a una dona del veïnat: "Lexeu vostra filla que m'ajudàs d'engranar la casa..." i també "de vegades la demanà per menar l'ast, e li agranave lo menjador e la cuyna, e la entrada ..."

Les escombres eren fetes amb un feix de branques o de palma i eren anomenades també graneres. Quan es fan inventaris de les cases no es citen les escombres, serien objectes de poc valor que ni s'esmenten; probablement es confeccionaven a la pròpia llar amb branques de boix, de bruc, amb fulles de palma o altres vegetals. L'inventari d'una botiga de Barcelona ens il-lustra sobre la venda de materials que es podien utilitzar per fabricar a casa escombres i altres estris de neteja: hi havia manolls de bruc i de farigola, "tupelles", és a dir flocs, d'espart, manades de cèrcols d'espart, cordes de cànem, de palma, de pell ${ }^{7}$.

La iconografia ens presenta alguna escombra formada per unes branquetes lligades al capdamunt amb un cordill, així veiem una dona que escombra al Livre des propiètés dels choses del $X V^{\beta}$ i també a les Lleis Palatines del rei de Mallorca veiem els escombradors reials amb dues escombres molt flexibles que semblen fetes de palma. Cap d'aquestes escombres no té mànec de fusta $o$ de canya, sinó que el mànec està format pel lligat del feix de branques pel cap d'amunt ${ }^{9}$.

\footnotetext{
5Jaume RiERA I SANS, El cavaller i l'alcavota, Barcelona, El Pi de les Tres Branques, 1973, p. 118.

${ }^{6}$ Ob. cit., pp. 79 i 87.

${ }^{7} \mathrm{AHCB}$, Notarial I-6 (Botiga de Mateu Birtó, 1436).

${ }^{8}$ Livre des propiètés dels choses, Biblioteca Nacional de Paris, MS Fr. 9140 f. 107 . Publicat a La dona medieval, Llibre d'hores il.luminat, Madrid, Mondadori España, 1988.

${ }^{9}$ Leges Palatinae, Palma de Mallorca, Govern Balear, 1991 p. 68.
} 
No totes es escombres que hi havia a les cases servien per agranar el terra, també trobem escombretes de pastera i escobretes d'espalmar.

\section{Orejar $i$ "espalmar" la roba}

La roba bona de vestir normalment es guardava dins dels arquibancs i cofres; no es rentava amb aigua ni amb cap altre producte, només s'orejava de tant en tant perquè no s'arnés i es raspallava abans de posar-se-la. Queda molt clara la tasca d'orejar les robes que ha de fer la muller d'un ciutadà en una carta que el ciutadà barceloní Arnau Climent Folquer envià al notari Narcís Gili: "si Na Joana vol orejar les gonelles ni la roba, obriu-li los cofres.... aprés torna-ho a tencar" 10 .

Per netejar la roba es feien servir una mena de raspalls que rebien el nom d'espalmadors o escombretes per espalmar la roba. A la botiga que hem citat abans hi havia "dotze escombretes de bruc per espalmar robes". Tant a les ordinacions de Pere el Cerimoniós com al llibre del Coc es diu que els servents dels gran senyors han d'ordenar la roba del senyor i que l'han de netejar i "espalmar aquella ab son espalmador" ".

\section{La bugada}

La bugada es feia de la roba de casa, llençols, estovalles, draps, tovallons, torcaboques, eixugamans, tovalloles, i també de la roba interior, és a dir camises i calces, de la roba dels infants i els davantals. Fer la bugada era una tasca laboriosa, hi havia algunes "lavaneres" professionals que s'hi dedicaven, però normalment les realitzaven les mestresses de casa dels estaments populars o les serventes a les llars que en tenien; només les classes privilegiades acudien de vegades a les bugaderes professionals, com ara Sança Ximenis que pagà diverses vegades els seus serveis a Salvadora Sunyera de Sant Cugat, "lavanera de la bugada" i encara no tot ho feia rentar fora de casa com consta en el llibre de comptes: "Memorial de roba qui.s levà de fora case"12.

\footnotetext{
${ }^{10}$ Epistolari del segle XV, Barcelona, Barcino, 1926, p. 62.

"Mestre RoBert, Libre del Coc, Universitat de Barcelona, 1977 p. 34.

${ }^{12} \mathrm{Ob}$ cit., p. 167, nota 3, entre d'altres.
} 


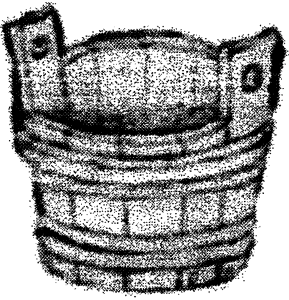

Gavadal

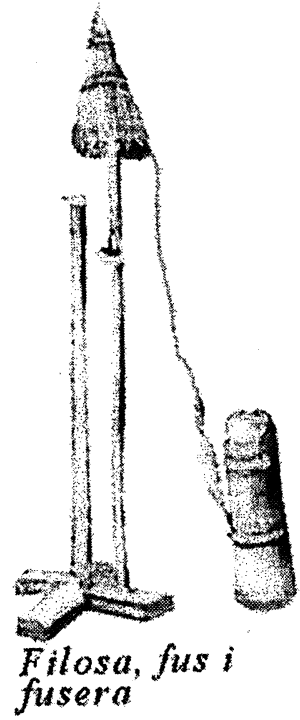

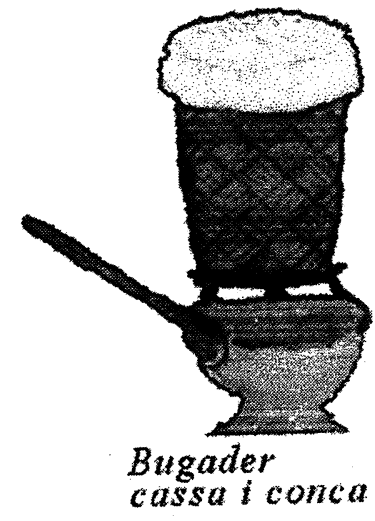

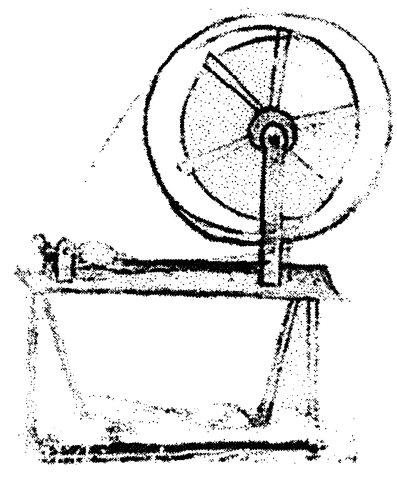

Torn de filar

L'utillatge de la llar 

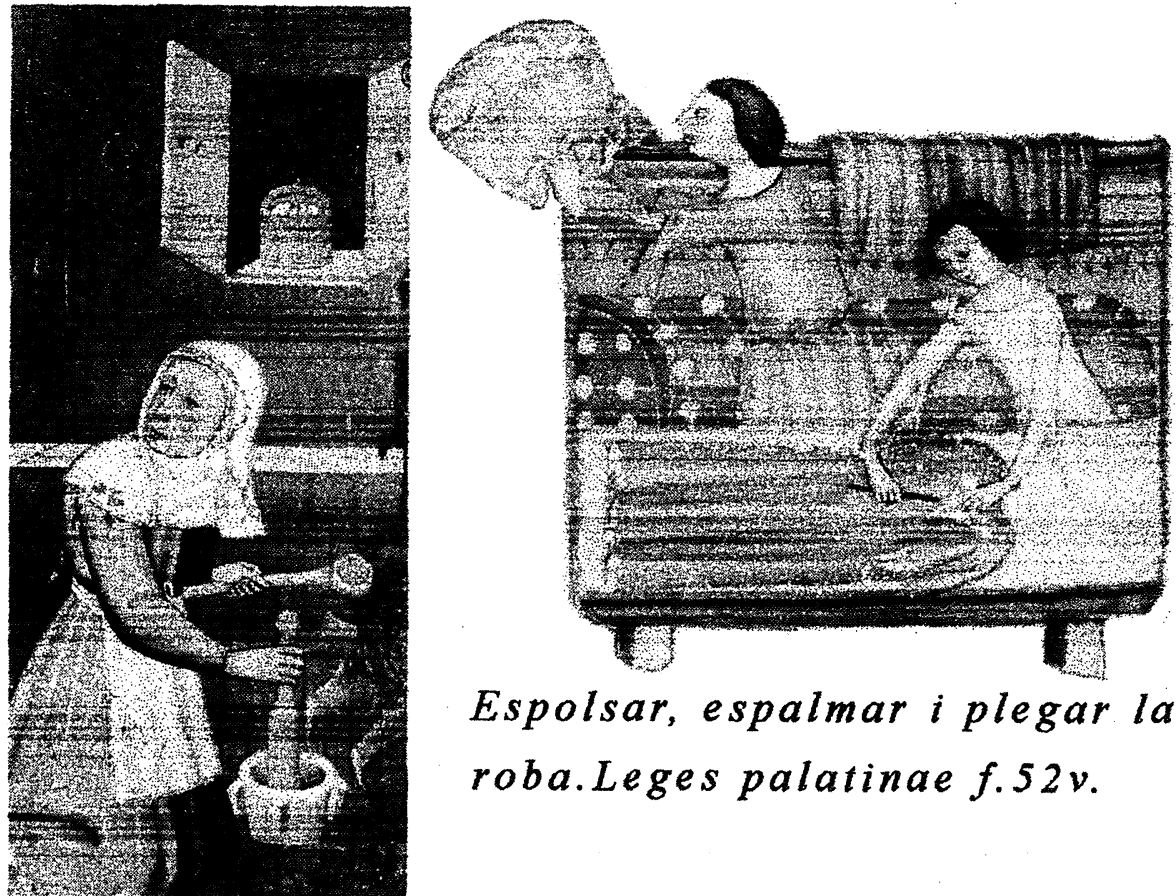

roba.Leges palatinae f. $52 v$.

\section{Cuina del S.XV. Taula del mestre de Cardona}

Història dels catalans 3, lam 41.

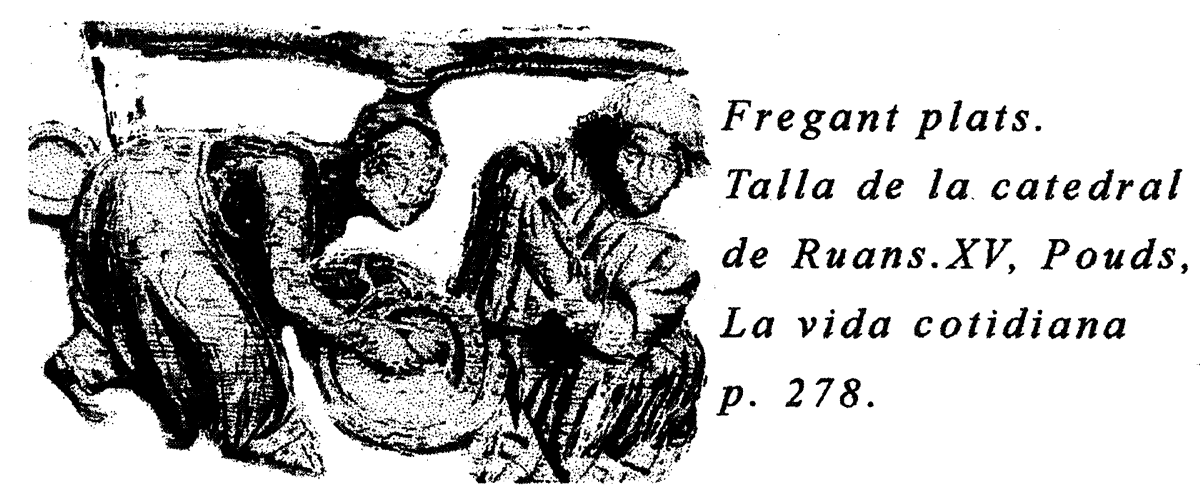


A Barcelona la bugada es feia normalment a casa, sovint en grans cossis que estaven a la cuina, també en trobem alguns a les entrades de les cases populars o a altres indrets de la casa de forma més excepcional. Així mateix hi havia al segle XV a la ciutat un espai públic on les dones podien rentar la roba, a la Ribera, i estendre-la als joncars que eren empriu de la ciutat; però en general la bugada es feia a casa per mitjà d'un procés força complexa que requeria una tècnica i un utillatge precisos.

De nou les Lleis Palatines de Jaume de Mallorca ens il lustren la tasca de la bugadera que va amb una cassa a la mà i que cola amb aigua calenta les cendres decantades damunt un cossi cobert amb un drap ${ }^{13}$. A totes les cases estudiades hi havia algun recipient per fer la bugada, normalment dos, que s'anomenen bugaders. cossis bugaders o pers, n'hi havia de diverses mides. Eren grans recipients que tindrien un forat a la part baixa, amb un tap per poder treure l'aigua. La majoria eren de terra, si bé trobem algun bugader escadusser de fusta; gairebé tots estaven enserpellats o encordats, és a dir folrats amb corda d'espart o d'altres fibres vegetals per protegir-los, i estaven posats sobre un banc o sella; alguns tenien cobertor, que podia ser de fusta o de ferro també hi havia algun bugader encastat a la paret de l'entrada. Altres estris per la bugada citats als inventaris són les casses normalment de coure amb un mànec llarg de ferro: "una cassa de coure amb son mànech de ferro apte per fer bugada. Una cassa bugadera ab son mànech de ferro" 14

Els estris de la bugada queden molt ben descrits a l'inventari de la casa barcelonina del donzell Joan Gener fet, l'any 1428: Dues calderes grans d'aram les quals servien per la bugada, dos cossis grans amb coberta de ferro per la bugada, una gerra amb cendra, uns draps de cadins per portar la bugada, un llençol de canemàs per cobrir la bugada ${ }^{15}$. A més de l'aigua calenta es feia servir cendra o lleixiu, que sovint es fabricava a casa amb cendra. En algun document trobem una caixa o gerra amb cendra, o bé gerres o alfàbies de tenir lleixiu, o un cogomar d'escalfar lleixiu, o un lleixiver, per exemple ${ }^{16}$.

\footnotetext{
${ }^{13}$ Ob. cit., p. 61, nota 9.

${ }^{14} \mathrm{AHCB}$, Notarials I-9 (donzell, 1449); I-3 (mercera s. XV).

${ }^{15}$ AHCB, Notarial I-6.

${ }^{16}$ T. GARCIA PANADÈs, Inventari del ciutadà Ferrer de Gualbes, "Acta Historica et Archaeologica Mediaevalia" 4 (1983); C. BATLLE Inventari de la casa de Pere Sangalda, mestre d'imatges, "Revista d'Història de Barcelona", 18 (1993).
} 


\section{Fregar plats}

El recipient més característic de l'alimentació medieval, que simbolitzava l'àpat quotidià, era l'escudella, per la qual cosa no ens pot estranyar que de la tasca de fregar la vaixella i els estris de cuina se'n digués rentar escudelles. Poques vegades ve aquesta tasca especificada als documents, ni tampoc no es troba representada a la iconografia. Era especialment una feina de les nenes i noietes joves a les famílies menestrals i camperoles, o bé de les serventes o esclaves a les llars benestants. De vegades, quan es llogava algun cuiner professional per atendre als nombrosos convidats dels enterraments, es llogava també una dona per fregar les escudelles.

De l'escadussera iconografia que ens representa aquesta feina quotidiana destaquem una talla de fusta de la catedral de Ruan en la qual es poden veure dues dones ajupides fregant plats; no es mostra cap contenidor per l'aigua, una de les dones fraga amb una mena de fregall que sembla fet amb un manyoc de fibres vegetals i l'altra asseca un plat amb un drap ${ }^{17}$.

Els inventaris barcelonins dels darrers segles medievals poques vegades citen un recipient concret per fregar-hi els plats, de tota manera a la majoria de les cuines hi havia contenidors grans: librelles i cossis de terra, gavadals de fusta o de terra, cubells i ferrades de fusta encercolada, conques de fusta i d'aram, peroles i olles metàl-liques de grans dimensions, tots aquests contenidors podien servir, entre d'altres coses, per netejar la vaixella, si bé en general no s'assenyala el seu ús. Destaquem algunes recipients que s'especifica que són per ensabonar, tots ells corresponen a inventaris del segle XV i no diuen que és el que s'hi ensabona: Una bacina d'aram d'ensabonar, una conca que servia per ensabonar, una conqueta petita apta per ensabonadora amb un peu d'aram, una caça de coure petita per ensabonar, una gerra de terra petita de tenir sabó; en una botiga de terrissa es troben sis librelles ensabonadores de terra ${ }^{18}$. Entre els inventaris estudiats hi trobem en concret una cassola d'aram de rentar escudelles i

\footnotetext{
${ }^{17}$ Pound, ob. cit., p. 278, nota 1.

${ }^{18}$ Corresponen als inventaris AHCB, Notarials I-14 (sabater, 1485); I-6 (donzell, 1428); I-12 (vídua d'un mercader, i botiga de terrissa, 1469).
} 
"dues gavetes de fust sotils abtes per rentar scudelles"19. Destaquem que tots aquests utensilis que tenen unes funcions similars reben noms diferents.

\section{Fer els llits}

Els llits es feien cada dia. Els llits medievals acostumaven a ser alts, a les cases burgeses tenien a més d'una màrfega de palla, diversos matalassos de llana i estaven posats sobre un entarimat de fusta i envoltats de bancs, cofres o caixes; els més luxosos estaven encortinats i tenien cobricel. Sempre hi havia llençols i un coixí llarg anomenat travesser, sovint també diversos coixins més petits anomenats orellers, tots ells acostumaven a ser de ploma. Hi havia flassades, vànoves i cobrellits. Els llits que veiem als retaules gòtics sempre estan perfectament fets, amb les vànoves ben estirades, i les cambres es veuen molt polides.

Sabem pel tesmtimoni d'un procés que una dona que tenia mal al braç es trobava amb certes dificultats per poder fer el llit ella sola: "ella deposant tenia mal al braç e la pregàs que se n'anàs ab ella e aiudar l'hi a fer lo lit" ${ }^{20}$. Una miniatura francesa del segle XIV ens representa dues dones fent un llit que allisen amb un bastó. Així mateix les miniatures de les Lleis Paletines mostren a dos servidors reials arreglant el $11 \mathrm{it}^{21}$.

\section{2. "Casta fuit, domum servavit, lanam fecit"22}

\section{Filar}

Aquest epitafi d'època romana ens mostra la tasca real i també simbòlica que ocupava a les dones de tots els estaments, no només a l'època romana sinó en els temps medievals, que era filar la llana o altres fibres tèxtils. En tenim infinitat de testimonis procedents dels grups socials més diversos. Eiximenis afirmava que les obres en les quals les dones se devien ocupar eren filar o teixir. "En especial se deuen ocupar les dones simples a

\footnotetext{
${ }^{19} \mathrm{AHCB}$, Notarials I-3 (mercera, segle XV).

${ }^{20}$ Jaume RIERA I SANS, ob. cit, p. 196, nota 5.

${ }^{21}$ Guillaume de DigulleviLle, Pelerinage de la vie humaine, Biblioteca Sainte-Geneviève, Paris, Ms. 1130 f.83. Reproduit ob. cit., nota 8; Leges Palatinae ob. cit. p. 66, nota 9.

${ }^{22}$ Mercè OTERO, La condición de la mujer a través de los textos latinos, Diputación de Málaga, 1992, p. 128.
} 
llur art, e les mijanes e simples deuen saber de cosir e de tallar çò que és necessari al marit, e a elles, e als infants, de roba de lli. Les dones major se deun ocupar en cosir de seda..."23. Afirmava que ja es deia des d'antic que "dona que no fila ja sab hom per qui és tenguda" $\mathrm{i}$ evoca una història romana segons la qual l'emperadriu havia decretat que la dona que no volgués filar fos exiliada de Roma i col·locada amb aquelles qui no filen, qui estan al bordell.

La iconografia ens mostra habitualment la dona filant: des de la Mare de Déu del mural que representa l'Anunciació de Sant Pere de Sorpe conservat al Museu d'Art de Catalunya, a Eva castigada a treballar després del pecat original dels capitells de Sant Cugat, L'Estany o Santes Creus, a dones del poble, com la pastora del retaule de Santa Margarida del museu episcopal de Vic o la dona que treu el cap per la finestra al retaule de la Nativitat de la Paeria de Lleida, totes elles estan filant.

També els documents escrits ens presenten dones de totes les classes socials, filant. Només a tall d'exemple citarem alguns fragments de processos que ens il·lustren sobre el tema: Joana, vídua de Guillem de Sobirats, mariner de Barcelona, que vivia al carrer d'en Robador, testimoni interrogada en un procés de 1376 afirmava que "aquesta testimoni fila lana en casa sua e no s'ha cura de les fahenes de les gents" 24 Una dona que declara com a testimoni en un altra procés diu: "Ella testes estava a la sua porta" (al carrer Comtal de Barcelona l'any 1379) "e filava tinent l'esquena girada envers la carrera. E axí stant oy brega prop casa d'ella testes e de continent pres dos infants seus e quatre d'altres e mes-los dins casa sua per pahor que havia que no fossin dampnificats ab les pedres que s.i tiraven..." ${ }^{25}$ Un home testifica en un altre procés, interrogat quina hora era quan aquest testimoni se va llevar del llit diu que era "alba clara et les vehines filaven ja en la carrera" 26 .

No només aquestes dones provinents de l'estament menestral sinó també les dones de la noblesa es dediquen a filar. Així la noble Sança Ximenis de Foix tenia organitzat a casa seva una mena d'obrador de

\footnotetext{
${ }^{23}$ Francesc EIXIMENIS, Libre de les dones, Universitat de Barcelona, 1981, I, cap. 16. Vegeu també Dotzè del Crestià, cap. 12.

${ }^{24} \mathrm{ACA}$, Procés en quart 1376-1378, fol. 33v.

${ }^{25}$ ACA, Procés 126/25.

${ }^{26}$ J. MiRET I SANS, Sembre han tingut bech les oques, p. 69
} 
filadura, en el qual treballaven ella, les dames que l'acompanyaven i les serventes $^{27}$. Així mateix les dones que estan a la presó comuna de Barcelona es veien oblidades a filar. "Te aparellades tantes filoses com hi ha fembres, e filen per la carcellera al menys fins a una hora aprés mija nit" ${ }^{\prime 2}$.

\section{Utillatge casolà per filat $i$ costura}

L'utillatge pels primers processos del treball de les fibres tèxtils depenien de la matèria primera, trobem cardes i pintes per cardar i pentinar la llana el lli i el cànem, masses per picar el lli, en un mas documentem un "banch larch ab sos petges abtes per a bregar cànem"29.

Però aquestes primeres tasques no es realitzaven a totes les llars urbanes, o al menys no en tenim esment a la majoria d'inventaris barcelonins, en canvi els utensilis que trobem amb més freqüència són debanadora, fusos i filoses. Un inventari interessant per analitzar els estris de filar és el de la casa d'un barquer barceloní, la muller del qual es devia dedicar a filar, que ens descriu amb precisió el següent utillatge: "Un peu de debanadora de ferre, gerres petites de terra amb serros de lli pentinat, una fusera de fusta $a b$ fusos; "un paner de vergues ab nansa en que havia una gran sort de fusos e fusades, una filosa de canya pintada e dues aspies de fust, tres debanadores de canya, unes aspilles de fust abtea aspiar lana, un torn abte a filar lana" 30 .

La debanadora és un aparell compost d'una mena de gàbia de barretes o canyes, que té forma lleugerament cònica i serveix per a anar traient el fil d'una troca o madeixa i enrotllar-lo formant un cabdell o omplint un rodet. També trobem esmentades les aspies $o$ aspilles, que tenien una funció similar, però que eren de forma més simple. La filosa servia per a filar a mà, era un instrument consistent en un bastó acabat per un extrem amb un cap o eixampla on s'enrotllava la floca per a filar. El fus, lligat a la filosa, estava format per una barreta rodona de fusta que va aprimant-se des del mig cap els extrems, amb una rotllana a la part més gruixuda, i que

\footnotetext{
${ }^{27} \mathrm{Ob}$. cit., nota 3 . Per exemple entre d'altres dades: 10 rams (de lli) eren filats de mà de madona Constaçe, "e los 23 de nosaltres totes", p. 105.

${ }^{28}$ Teresa VINYOLES, Queixes dels pobres presos de la presó de Barcelona, "Acta Historica et Archaeologica Mediaevalia", 18 (1997), p. 77.

${ }^{29} \mathrm{AHCB}$, Notarial I-10 (Rubí, 1460).

${ }^{30} \mathrm{AHCB}$, Notarials I-8 (1446).
} 
impulsada amb els dits serveix per a tòrcer el fil i enrotllar-lo a mesura que es forma. El torn de filar, que trobem documentat moltes menys vegades, és una filosa més evolucionada ja que hi té aplicada una roda que es fa girar per mitjà d'un mànec. En una casa del carrer Fonollar de Barcelona, l'any 1458, s'inventaria, a l'entrada, un torn de filar llana i un aspiell de fusta d'aspiar llana i, al menjador, una fusera de fusta en la que hi ha dos aspiells, 14 fusos i una llanterna; encara, en una cambra, hi ha una filosa ${ }^{31}$

A més per confeccionar els vestits i complements de la indumentària s'empraven tisores, agulles d'os o de ferro, didals, rodets, per fer les xarxes i les gandalles, que podien ser fetes de fusta o d'os; agulles per fer calces d'agulla, molt probablement de ferro. No en trobem inventariats telers a les llars urbanes, tret de les cases dels professionals teixidors, en canvi la iconografia ens mostra telers domèstics ${ }^{32}$.

Bona part de les dones urbanes també sabrien fer treballs més delicats amb seda i brodats. Així la filla d'una lliberta, serventa d'un taverner de Barcelona, ens explica com obrava una trena de bastons d'or i de seda verda pel seu enamorat, que "serví embotonar lo jupó devant e los punyets del jupo e feu-la ella deposant be ha més de un mes en digmenge de nit e de die...la qual seda e or lo dit Matheu pagà e li tramès... Matheu venc a la porta de la dita casa ben vespret e ella deposant lensalí la dita trena de la finestra de la casa dins un paper embolicada ab la seda qui y era sobrada" 33 .

\subsection{L’alimentació}

\section{El foc}

Calia mantenir el foc de la llar que ben sovint restava encès sempre. En cas de que s'apagués el foc s'havia de tornar a encendre per mitjà d'un

\footnotetext{
${ }^{31}$ AHCB, Consellers XI, c. 7.

${ }^{32}$ Com ara la miniatura de la Sagrada Família del Llibre d'hores de Caterina de Cleves (Utrecht 1440). En aquest sentit és interessant el que diu Isabel e Villena a la "Vita Christi": "La Senyora veent que lo guany de la filosa era molt poc, dix a Josep que li fes un teler", $o b$. cit. p. 249

${ }^{33} \mathrm{ADB}$, Procés 1427 , fol. 40r.
} 
esclavó, que era una peça de ferro que servia per encendre el foc, donant cops a una pedra foguera; ${ }^{34}$ o anar a cercar caliu a casa d'alguna veïna ${ }^{35}$.

Pel que fa als estris necessaris per la llar trobem als inventaris barcelonins: manxes per bufar el foc, molls de ferro, "una giradora de ferro la qual dix serveix per treure caliu" ${ }^{36}$. Penjats a la llar hi havia els clamastres o cremalls amb el seu guarniment i les lleves per treure les olles del foc, damunt les brases els trespeus per sostenir olles i cassoles, tots aquests instruments eren de ferro. A la casa d'un ric mercader trobem un objecte molt especial: "Dos cavalls de ferro ab dos caps de animals entortolligats en lo mig embotats de botons de ferro, grans, que servien per fer gran foc" ${ }^{37}$.

A part de la llar, trobem de vegades documentats altres tipus de fogons que es fa força difícil d'imaginar com eren i que ens limitem a citar tal com com estan descrits als inventaris. Els més normals són fogons de ferro de tres cases o de tres olles; n'hi ha algun de quatre i fins de cinc cases; també n'hi ha de coure i d'aram: Un fogó d'aram amb sos anells, un fogó de coure gran "ab dues nanses e launes de ferro", un fogó de coure amb el qual se cuina amb carbó, un fogó rodó de coure ${ }^{38}$. Alguns d'aquest fogons es diu que són amb corrioles: un foguer quadrat migencer de ferre amb quatre peus amb corrioles, un fogó de fusta corredís o amb corrioles, un fogó o llar de ferro amb quatre peus i corrioles i quatre anells ${ }^{39}$.

\section{Pastar}

El pastador, tant si és un espai exclusiu per aquesta tasca, com si es troba inclòs a la cuina, al porxo, a l'entrada o al rebost, o encara que sigui una senzilla pastera en un racó, es troba a totes les llars estudiades. Els

\footnotetext{
${ }^{34}$ Isabel de Villena ens parla d'aquest instrument que li dóna Anna a Maria quan marxa vers Egipte: "ve-us ací un esclavó perquè pugau encendre foc". Protagonistes femenines de la "Vita Christi", Barcelona, La Sal, 1987, p. 34.

${ }^{35}$ Un procés mallorquí ens descriu una escena protagonitzada per dues camperoles que anaren a buscar foc a la cuina d'una casa veïna per portar-lo a les seves cases. Gabriel BIBILONI, Libre d'inquisicions de la cúria reial de la parròquia de Castellitx (1379-1388), Algaida, Consell Insular de Mallorca, 1997, p. 161

${ }^{36} \mathrm{AHCB}$, Notarial I-6 (casa d'un mercader, 1430)

${ }^{37} \mathrm{AHCB}$, Notarials I-10 (1457).

${ }^{38} \mathrm{AHCB}$, Notarial I-10 (mercader, 1457); I-3 (mercera s. XV).

${ }^{39}$ J.M. CASAS Homs, "Cuadernos de Historia Económica de Cataluña" (1969), pp. 9-112; AHCB Notarial I-8 (barquer, 1446); AHCB I-3 (mercera s.XV); I-12 (ciuitadà, 1468).
} 
utensilis per poder pastar el pa consistien en una pastera de fusta, de vegades amb cobertor i peus. A les cases més benestants n'hi havia dues, una per pastar el pa blanc pels senyors i un altra per pastar pa d'inferior qualitat pel servei. Hi trobem a més les posts de pastar i la de dur el pa al forn, recipients de diversos materials per guardar-la farina, escales de fusta i sedassos de seda per passar la farina, l'escombreta per netejar les posts de pastar, els draps de cànem o de llana per cobrir la massa, la raedora de ferro que servia per separar la massa de les parets de la pastera i per tallar els pans abans de coure'ls. Hi trobem també paneres per posar-hi el pa un cop cuit i de vegades la senyal de senyalar el pa, que servin per conèixer el pa que s'havia pastat a casa i que havia portat a coure al forn.

\section{Conservar i emmagatzemar aliments}

$\mathrm{Al}$ rebost els contenidors eren majoritàriament ceràmics espcialement per oli, mel, llegums, conserves de vegades fetes a la pròpia llar, sobretot trobem gerres de fer olives, però també per salar peix, i barrils, és a dir recipients de fusta, per tenir anxoves. Les conserves es feien amb sal, amb oli o amb vinagre; no només es podien fer a casa, sinó també comprar-les fetes i sempre s'havien de vigilar perquè no es perdessin: “Aquesta és per avisar-vos com per lo navili d'en Tarascó tramet cert oli e una gerra de savoges salades per a casa e per a mos amics... E és mester tantost sien arribades les destap e damunt les esbrom del rovell que roda damunt; altrament se perdrien, e fa fer sovint" ${ }^{40}$.

A la majoria de cases, fins i tot urbanes, hi havia un celler per guardar-hi el vi, sovint s'hi elaborava el vi, ja que moltes de les cases tenen cups de fusta, algun es diu que es de fusta de roure. Tret de les cases més humils la resta tenen cellers amb diverses botes; les cases senyorials tenen diversos cellers: un és pel vi blanc, a l'altra hi ha el vi comú, és a dir negre, el vinagre etc. En els cellers dominen els contenidors de fusta encercolats: vaixells, botes, carretells, portadores. Hi ha sempre alguns embuts, n'hi ha de grans per "metre vi per les botes" i de petits per treure el vi de les botes. I també trobem l'utillatge per elaborar el piment i la clareia: pimenteres de ceràmica i manegues de canemàs per fer clareia.

\footnotetext{
${ }^{40}$ Epistolari del segle XV, Barcelona, Barcino, 1926, p. 63.
} 


\section{Cuinar}

El primer que cal dir és que no hi ha cap cuina igual. De tota manera podem establir a les llars urbanes dues tipologies de cuines, la majoria eren cuines petites on no hi acostumava a haver gaires objectes, fet que es pot entendre ja que la llar de foc els fumava. També hi havia d'altres cuines més grans a les que s'hi desenvolupaven afers diversos, a més de coure-hi els aliments, s'hi pastava, s'hi feia la bugada o s'hi menjava.

En general eren cuines amb llar de foc a les que s'hi troben objectes majoritàriament metàl-lics: un element indispensable és l'ast, a moltes cases n'hi havia més d'un de mides diverses, i també el menador d'ast dit també capferrer o cavall de ferro de menar l'ast. Així a la cuina d'un ric mercader hi trobem: "un gran ast de ferro ab son peu en què roda, un altre ast gran, tres ast de ferre petits, un cap ferrer de menar l'ast amb tres peus". També hi havia paelles amb les seves giradores, la majoria es diu que són de ferro només alguna era d'aram, graelles, losses i esbromadores, tot això de ferro. A més a les cuines hi havia peroles, calderes, calderons, casses, bacins, conques, olles i cassoles.

Hem d'assenyalar que a les cases benestants els recipients per cuinar, incloses les olles $i$ les cassoles, eren metàl-lics, en veurem un exemple a la cuina que acabem de citar: "Una olla de coure gran de capacitat de 20 escudelles, una olla de coure gran de capacitat de 16 escudelles, una olla de coure gran de capacitat de 18 escudelles, una olla poqueta de capacitat de 8 escudelles, una olla de coure petita de capacitat de 4 escudelles. Cobertores d'olla de ferro. Una cassola d'aram de capacitat de 10 escudelles, tres cassoles mitjancera d'aram de capacitat de 6 escudelles, dues de dins estanyades, una cassola poqueta d'aram de capacitat de 4 escudelles" ${ }^{\prime 1}$.

Algunes cases de menestrals i camperols tenien recipients tant de metall com de terra, així a la cuina d'un barquer hi havia: "Una olla de coure gran, dos calderons d'aram amb nansa de ferro, quatre olles e dues cassoles e dues cobertores de terra, dues olles de terra, una gran e una pocha; dues cassoletes de terra poques" ${ }^{42}$. Les cuines més humils no tenien olles metàl-liques, així per exemple la vídua d'un mariner, força pobre, tenia

\footnotetext{
${ }^{41}$ Aquestes dades $\mathrm{i}$ les anrteriors són de la casa del carrer Lledó, publicada per CASAS HoMs, ob. cit., nota 38 .

${ }^{42}$ AHCB, Notarial I-8 (1446).
} 
només per a cuinar una paella d'aram de poc valor, tres olletes de terra poques i una cassoleta de terra ${ }^{43}$.

Els habitacles més senzills no tenien cuina; les persones de grups marginats vivien en entrades que feien d'obrador, menjador, rebost i cuina a la vegada, i damunt tenien un sostre on hi dormien. Aquestes llars més senzilles disposaven per a cuinar només d'algun atuell, majoritàriament de terrissa, i d'un fogonet d'aram o de terra. Pel que es desprèn de l'inventari d'un pobre mendicant, aquest disposava d'una paella de ferro amb la seva giradora, tres olles i dues cassoles de terra i un fogó juhesch ${ }^{44}$. Creiem que el fogonet rebia aquest nom perquè les mestresses de casa jueves preparaven el menjar del dissabte el divendres per no haver de treballar el dia prohibit, llavors el dissabte s'escalfava damunt d'un fogó.

Uns estris imprescindibles a les cuines medievals eren els morters per fer picades i salses. N'hi havia de terra, marbre, pedra de Girona, coure, fusta. Moltes cases disposaven de diversos morters, cada un dels quals podia donar una textura diferent als aliments que s'hi picaven.

Els estris de cuina generalment no es diu per què es feien servir, però en trobem alguns que es citen amb els usos concrets entre els que donem alguns exemples: un girador de ferro per girar peix, un rall per ratllar formatge, una castanyera de coure per torrar castanyes, un cabasset de dos nanses per portar magranes, "un sedàs gran de serres e un altre poch de passar salsa", un embut d'estany "dos trahedors per traure oli", una destraleta per tallar cansalada, una paella molt petita per coure un parell d'ous, amb sa cua. També es citen atuells específics per cuinar plats concrets: "unes tudoneres o scudelles de terra abtes a debatre todons de obra de València. Una cassola gran de coure la qual servia les mes vegades per fer janet" ${ }^{\text {45. }}$.

\section{CONCLUSIONS}

Hem constatat que es fa difícil separar l'utillatge de la llar de les tasques domèstiques i d'altres elements que estan relacionats amb el que

\footnotetext{
${ }^{43}$ AHPB, S. Carner 1415-1429, fol. 22 ss.

${ }^{44} \mathrm{AHCB}$, Notarial I-12 (1468).

${ }^{45}$ T. Garcia PanadÈs, ob. cit., nota 16; AHCB, Notarial I-6 (1430), respectivament.
} 
podem anomenar parament de la llar. Caldria fer un anàlisi en paral·lel dels objectes que ens mostren el grau de confort de les cases, és a dir que ens poden apropar a la qualitat de vida, així com ara els tipus diversos de llumaners, sistemes d'abastament i d'evacuació d'aigües, atuells per la higiene personal, per la medicina i cosmètica casolanes. Aquests temes escapen de la finalitat del nostre treball, però els considerem un complement important del mateix. ${ }^{46}$

Les tasques de la mestressa de casa, deixant de banda les fonamentals de l'administració de la llar i la cura dels infants, les podem dividir en tres blocs: les relacionades amb la neteja i confort de la casa, les destinades a la confecció i cura de la roba, i les vinculades a l'alimentació familiar.

Volem remarcar que la major part de les tasques de la llar les feien les dones ajupides o assegudes en cadires molt baixes anomenades cadires de dones; i també que bona part de les cases, de tots els estaments, eren veritables obradors en els quals es realitzaven les tasques més diverses i a la vegada eren les escoles, les úniques escoles, per les noves generacions de dones que aprenien de llurs mares o mestresses infinitat de tasques i a fer servir l'utillatge necessari per realitzar-les.

Remarquem és les funcions i els objectes quotidians perduren molt en el temps, la vida de cada dia s'anava transformant lentament de generació en generació, de forma gairebé imperceptibles. També constatem que l'utillatge de la llar té formes i solucions força semblants arreu de l'Europa Occidental com es pot veure per les fonts iconogràfiques.

\section{RÉSUMÉ}

Dans ce travail on a etudié les besognes domestiques et le ménage qu'on utilise pendant le $\mathrm{XIV}^{\mathrm{e}}$ et $\mathrm{XV}^{\mathfrak{e}}$ siècles. On a fait la recherche en utilisant des inventaires et de l'iconographie. On a travaillé les nécéssités basiques: l'abri, le vêtement, le nettoiement, l'aliment; mais aussi on a pu constater que les maisons sont des étaliers ou on fait

\footnotetext{
${ }^{46}$ En aquest sentit hem documentat per exemple un got de vidre "aptum a levar neulella" (malaltia que dona dolor al final de l'esternó inici de l'estòmac); "unes mànegues de crestilis". és a dir per posar lavatives; però, especialment, a moltes de les llars hi trobem alambins que ens mostren el coneixement del procés de destil-lació per part d'un bon nombre de dones medievals.
} 
l'élaboration des produits divers, et elles sont aussi des écoles où les filles peuvent aprendre infinité de besognes et l'utilisation des utensiles necessairs.

\section{SUMMARY}

The aim of this paper is to study domestic labour and utensils used in this job during XIVth and XVth centuries. The investigation has been done about inventories and iconography. It has been worked about basic needs: shelter, cleanness, clothes, food. It has been shown that houses were a workshop where the people elaborated different products and it was also the school where the girls were instructed about the utensiles use. 